\title{
Editorial
}

\section{The human squamous epithelial cell envelope: the structural model by Peter M Steinert}

\author{
E Candi ${ }^{*, 1}$ and G Melino ${ }^{1,2}$ \\ Cell Death and Differentiation (2013) 20, 965-966; doi:10.1038/cdd.2013.58
}

This year is the 10th anniversary of the unexpected premature loss of Peter Steinert, an original editor of our journal 'Cell Death and Differentiation'. Peter M Steinert (1945-2003) ${ }^{1}$ was born in Australia and received his PhD in Biochemistry from the University of Adelaide, South Australia. There he worked with Professor George E Rogers on wool proteins. In 1973, after post-docs at Boston
University and the Massachusetts Institute of Technology, he opted to join the Dermatology Branch of the National Cancer Institute. In 1990, he was appointed as the Head of the Laboratory of Skin Biology within the National Institute of Arthritis and Musculoskeletal and Skin Diseases (NIAMS), part of the National Institute of Health at Bethesda, Maryland (Figure 1).

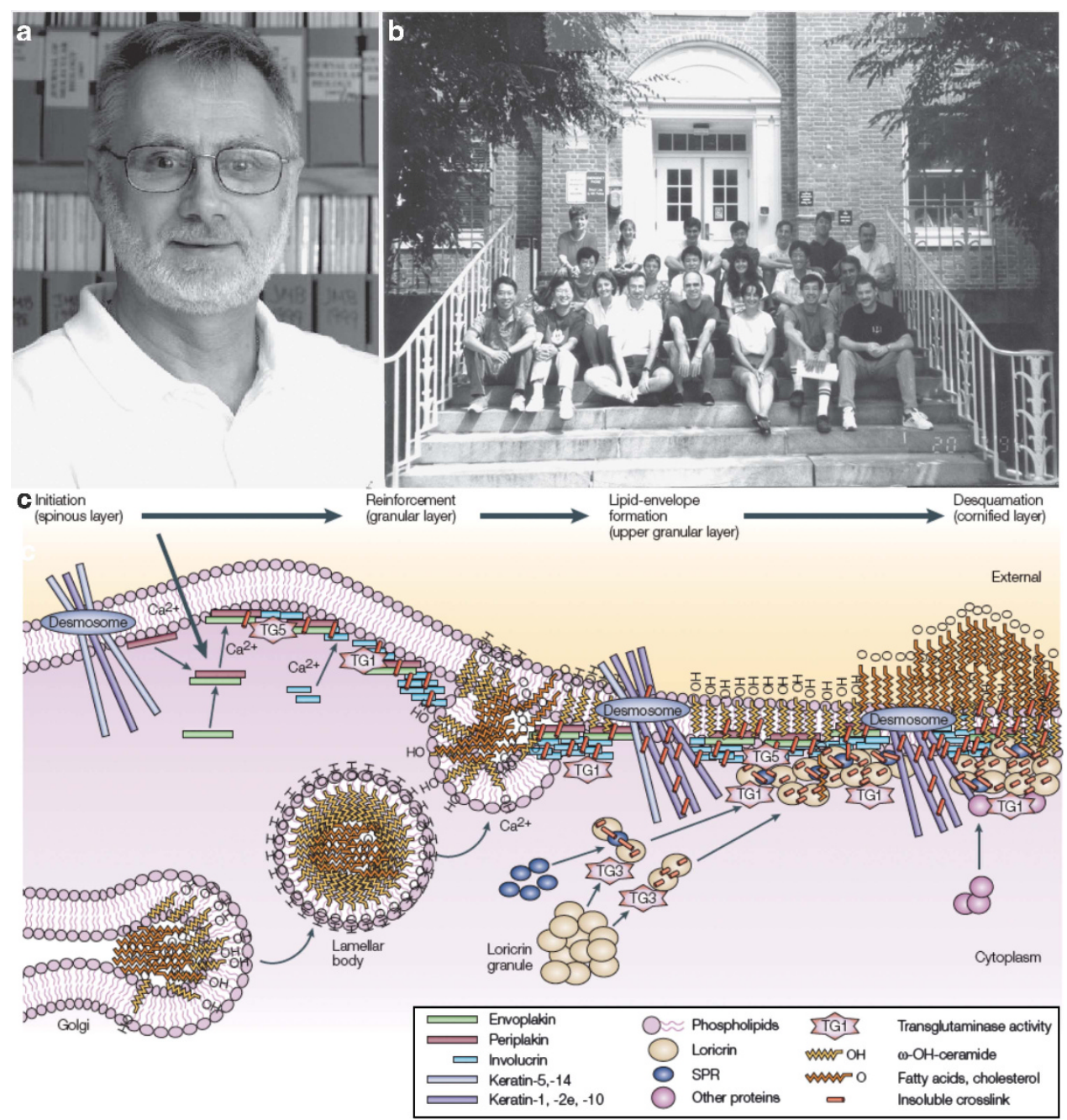

Figure 1 Dr Peter M Steinert (1945-2003) (a) and his laboratory (b). Structural model of the cornified model, ${ }^{2}$ as modified in the study by Candi et al. ${ }^{4}$ (c)

\footnotetext{
${ }^{1}$ Department of Experimental Medicine and Surgery, University Rome Tor Vergata, Rome, Italy and ${ }^{2} \mathrm{MRC}$ Toxicology Unit, Leicester, UK ${ }^{*}$ Corresponding author: E Candi, Department of Experimental Medicine and Surgery, University Rome Tor Vergata, via Montpellier 1, 00133 Rome, Italy. Tel: +390672596487; Fax: +390672596977; E-mail: candi@uniroma2.it
} 
Peter Steinert's interests were epidermal proteins and other features of pluristratified epithelia, including structural proteins and enzymes, alike. This elucidated numerous molecular mechanisms underlying various dermatological disorders - not least the ichthyoses. Peter Steinert's major achievements included studies on keratins structure and keratin-intermediate filament assembly; identification of novel, cornified-cell-envelope components; characterisation of enzymes involved in their cross-linking (TGs, transglutamisases) - including the three-dimensional structure of TG3; identification of the biochemical steps leading to cornifiedcell-envelope assembly.

On the occasion of the 10th anniversary of the death of Peter, ${ }^{1}$ and in recognition of his unique contribution to science, and in particular the field of dermatological biology, we propose that the model ${ }^{2}$ that Peter published in Cell Death and Differentiation (CDD) in 1995 be discussed here. Peter M Steinert developed an accurate method to dissect biochemically the cornified-cell envelope (CE) of the human epidermis, examining protein and lipid components. He was able to confirm that the CE comprises a protein and a lipid constituent, necessary to provide a vital physical barrier in mammals (Figure 1c). ${ }^{3,4}$ The protein component is a 10-nmthick layer of highly insoluble and cross-linked proteins deposited on the intracellular side of the plasma membrane of differentiated keratinocytes in the epidermis or in epithelial cells of other stratified squamous epithelia, Figure 1c.

In 1995, Peter Steinert and his colleague, Lyuben Marekov, published a paper on the order of assembly of the proteins elafin, filaggrin, keratin filaments, loricrin, and small prolinerich proteins (SPRs) 1 and 2, cross-linked by TGs in the CE. ${ }^{5}$ Several indirect data were available at that time, suggesting that these proteins were components of the CE. However, to design experiments to demonstrate that they were directly involved had proven difficult, due to isopeptide cross-links that could not be hydrolysed to release intact proteins without the use of reagents that also cleaved the peptide bounds. Peter Steinert developed an accurate method, using limited proteolytic digestion, to establish biochemically how these proteins are cross-linked, in which order and which aminoacid residues in the proteins were utilised in cross-linking. ${ }^{5}$ Human CEs, purified from the foreskin epidermis, were digested with proteinase $\mathrm{K}$, releasing soluble peptides corresponding to $30 \%$, and subsequently to $35 \%$, of the CE protein mass. The recovered peptides corresponded to the outer third (cytoplasmatic surface) and middle third of the CE, respectively. This method allowed the recovery of 145 unique peptides containing either a single peptide or diverse peptides associated with cross-linking. The peptide sequencing, overall, demonstrated that the outer third of the CE structure consists of inter- and intrachain cross-linked loricrin with
SPR1, SPR2, the latter as bridging proteins between loricrin. The middle third of the CE consisted of loricrin and SPR crosslinking, mixed with cross-linked elafin, keratins $1,2 e$ and 10 , as well as filaggrin. In his $C D D$ article, ${ }^{2}$ Peter Steinert presented a model for the intermediate-to-final stage of CE assembly in which the proteins loricrin, SPR1 and SPR2 were deposited on a preformed scaffold; later elafin, was included. In addition, the fact that keratins and filaggrin were found, cross-linked to CE components, demonstrated unequivocally that the cytoskeleton was chemically linked to the CE. Further studies, using the same methodological approach, completed the analysis of the CE by analysing the inner third. ${ }^{5}$ This described, based on direct evidence, that involucrin was a major, isopeptide-cross-linked component of the inner CE. ${ }^{6}$ Peter M Steinert and Lyuben N Marekov then analysed the CE externally, by partial saponification of isolated, foreskinepidermal CEs, followed by limited proteolysis, with the aim of discovering the earliest events in CE deposition. ${ }^{7}$ They recovered several lipopeptides and, using mass spectroscopy, found that the majority of the lipids were ceramides. Amino-acid sequencing revealed that $35 \%$ of the lipopeptides contained the glutamine-glutamate-rich regions of involucrin, while a further $18 \%$ contained sequences of envoplakin and periplakin. Together, these data indicated for the first time that periplakin and envoplakin, components of the desmosomes, were part of the CE and that periplakin, envoplakin and involucrin act as a substrate for ceramide attachment, by ester linkage to the $C E$, necessary for barrier function in the human epidermis. Further experiments carried out by Peter Steinert and his collaborators on ceramide-CE-protein attachment mechanisms have revealed that TG1 is responsible for the catalysis of the ester bond. ${ }^{8}$

Peter M Steinert passed away suddenly on the 7th April $2003,{ }^{1}$ this current year marking the first decade since his sad departure. His immense professional contribution to the field of dermatological biology is clearly illustrated by no fewer than 380 articles published since 1990, with well over 18000 citations ( $\mathrm{H}$-index 78), not to mention the articles published in our journal. ${ }^{2,9}$ Peter M Steinert is sorely missed, while his endeavours continue to produce conceptual advances that will ensure his long-lasting influence in this area of expertise.

\footnotetext{
1. DiGiovanna JJ. Cell Death Differ 2003; 10: 1117.

2. Steinert PM. Cell Death Differ 1995; 2: 33-40.

3. Kalinin A, Marekov LN, Steinert PM. J Cell Sci 2001; 114: 3069-3070.

4. Candi E, Schmidt R, Melino G. Nat Rev Mol Cell Biol 2005; 6: 328-340.

5. Steinert PM, Marekov LN. J Biol Chem 1995; 270: 17702-17711.

6. Steinert PM, Marekov LN. J Biol Chem 1997; 272: 2021-2030.

7. Marekov LN, Steinert PM. J Biol Chem 1998; 273: 17763-17770.

8. Nemes Z et al. Proc Natl Acad Sci USA 1999; 96: 8402-8407.

9. Steinert PM et al. Cell Death Differ 1999; 6: 916-930.
} 